\title{
Processing of pre-impregnated thermoplastic towpreg reinforced by continuous glass fibre and recycled PET by pultrusion
}

\author{
M. Asensio ${ }^{\text {a, }}$, P. Esfandiari ${ }^{b}$, K. Núñez $^{\text {c }}$, J.F. Silva ${ }^{\mathrm{b}}$, A. Marques ${ }^{\mathrm{d}}$, J.C. Merino ${ }^{\mathrm{a}, \mathrm{c}}$, J.M. Pastor ${ }^{\mathrm{a}, \mathrm{c}}$ \\ ${ }^{a}$ Department of Condensed Matter Physics, Escuela de Ingenierías Industriales, University of Valladolid, Paseo Del Cauce, 59, 47011, Valladolid, Spain \\ ${ }^{\mathrm{b}}$ ISEP-School of Engineering, Polytechnic of Porto, Rua DR. António Bernardino de Almeida, 431, 4200-072, Porto, Portugal \\ ${ }^{\mathrm{c}}$ Foundation for Research and Development in Transport and Energy (CIDAUT), Technological Park of Boecillo, 47051, Valladolid, Spain \\ ${ }^{\mathrm{d}}$ DEMec / FEUP, R. Dr. Robert Frias, $s / n, 4200-465$, Porto, Portugal
}

\section{A R T I C L E I N F O}

\section{Keywords:}

Thermoplastic resin

Pultrusion

Recycled

Glass fibres

\begin{abstract}
A B S T R A C T
Packaging sector generates $40 \%$ of the plastics consumption in Europe. Among the most consumed plastics, polyethylene terephthalate (PET) is still the material that undoubtedly continues to grow in the packaging sector. Hence, there is a concern related to the recycling process, which today is only around 56\%. Therefore, the objective of this work focuses on the use of this recycled material as a source of raw material for pultrusion processes. This work studies and compares the processability of final composite pultruded parts by using three different pre-impregnated recycled materials different in their viscosity and stream. Those composites were characterized by mechanical testing and microscopy analysis. The obtained results were compared with those of another pultruded thermoplastic (polypropylene) composite. From this study, it was possible to transform a waste into a product with high added value, reducing the carbon footprint.
\end{abstract}

\section{Introduction}

Polyethylene terephthalate (PET) is a lightweight material commonly used for the manufacture of containers and packaging [1]. Although PET is totally recyclable, due to the problems with its mechanical recycling and post-processing, millions of tons end up in landfills and oceans every year, needing, possibly, hundreds of years to decompose [2,3]. Most of the problems comes from highly printed containers (multilayer and/or metallized) and pose new challenges for recycling systems, regardless of whether it is production waste or post-consumer materials. Multilayer containers are very difficult to recycle because many different polymers containing metals and colors form them. In addition, they have the compatibilizing agents and other additives that are in the inks obtaining products with poor mechanical properties [4,5].

Current recycling alternatives reuse PET waste in low-value and short-lived applications such as in packaging sector, becoming a waste again in a very short time of use. Recycling in the packaging sector focuses on using the cleanest PET fractions (especially those made up of transparent flakes) leaving aside the recycling of the most contaminated fractions. Moreover, packaging applications require very demanding and expensive material cleaning cycles. As a consequence, recycled and waste thermoplastics, such as PET, are some of the major components of global municipal solid waste and present a promising raw material source [6]. For this reason, other processes are currently being sought to introduce any stream of PET waste, including coloured PET, as a raw material to obtain products with a long useful life and high added value such as composites.

To solve the problems that recycled materials present in terms of poor mechanical properties are usually reinforced with short fibres. Current studies have proposed using these PET wastes as matrices in composites [7,8]. One of the most widely used methods of manufacturing composites is the pultrusion process in which no studies of the use of recycled PET material as a matrix are found. Pultrusion involves a high demand process and is one of the available manufacturing processes to produce polymeric composites with a constant cross-section profile in a continuous manner [9]. Currently, most materials used in composites are based on thermoset matrices. Due to the actual recyclability problems of thermoset materials, the introduction of thermoplastics materials in this process is increasing. The capability to flow with heat makes thermoplastics recyclable and post-formable materials [10]. In addition, composite materials with thermoplastic matrices offer greater resistance to fracture, higher impact resistance, greater toughness and damage tolerance, a shorter

\footnotetext{
* Corresponding author.

E-mail address: marase@cidaut.es (M. Asensio).
} 
processing time and excellent environmental stability $[9,11,12]$.

However, the use of composite materials of thermoplastic matrix reinforced with long/continuous fibre implies great technological and scientific challenges since thermoplastics have a much higher viscosity than thermosets, which hinders the impregnation and consolidation process. The thermoplastic prepregs mitigate this problem, since it is an intermediate product prepared to facilitate its further processing [13]. Prepregs are usually produced by two techniques. The first consists of the direct fusion of the polymer that allows the manufacture of pre-consolidated tapes (PCT) [14]; the second method is carried out by a process of intimate contact with the matrix in the form of powder, which is the process of manufacturing "towpregs". These processes have been widely tested using polypropylene matrices [15-17].

This work proposes as a solution for recycling PET waste by its introduction as a thermoplastic matrix pultruding the towpreg to make composites parts. The process of intimate contact before manufacturing (towpreg) is probably the most viable way to use recycled PET as matrix, since this process is less constrained by the properties of the recycled materials. Due to its high viscosity compared to thermoset materials it is important to study the fluidity of these recycled materials as well as the relationship of the viscosity and impregnation with the final properties of the composites obtained.

In this work it has been studied two streams of recycled material, a cleaner one that comes from translucent and blue bottle streams and another recycled PET which comes from a more contaminated stream that contains coloured and multilayer PET material. These materials come from different waste streams and have different rheological properties, so the influence of this parameter on the final properties of the final profiles will be studied. In addition, recycled PET chemically modified with low viscosity was studied for the manufacture of pultruded composite profiles [18].

The final composite parts were submitted to tensile, flexural test, as well calcination and optical microscopy. To see the feasibility for industrial applications of profiles obtained with PET matrix a comparison of properties with another thermoplastic polymer (polypropylene) already introduced in pultrusion from towpregs has been made [12]. Polypropylene can easily be processed because of the low melting and process temperature; whereas polyethylene terephthalate requires a higher process temperature, but offers better temperature resistance [19].

\section{Experimental}

\subsection{Raw materials}

Three materials from recycled PET were used to manufacture the pultruded profiles. Unmodified PET (PET 1) belongs to a stream of recycled PET that mostly contains blue and transparent flakes from bottle waste (blue PET). Modified PET (PET 2) comes from a previous investigation in which this recycled PET 1 was chemically modified in order to get lower viscosity values to achieve better impregnation. The chemical modification was performed by reactive extrusion with an amount of $0.25 \%$ wt $\%$ of 5-aminoisophthalic acid [18].

PET 3 comes from streams with multi-layered and coloured recycled PET (colour PET). All the recycled PET materials were supplied in the form of flakes by ClearPET. These flakes were extruded at $265{ }^{\circ} \mathrm{C}$ and $100 \mathrm{rpm}$. Then, these pellets were converted into powder by mechanical crushing with liquid nitrogen, passing it through sieves for particle size control. Summary of properties of materials used are shown in Table 1. The Young Modulus and Tensile Strength properties of PET matrices were determined in accordance to ISO $521-1$ at a speed of $1 \mathrm{~mm} / \mathrm{min}$ and $10 \mathrm{~mm} \mathrm{~min}^{-1}$. The intrinsic viscosity was determined under ASTMD4603-03. Molecular weight was determined by Gel permeation column (GPC) [18]. Density under ISO 1183-1. Fibre diameter was evaluated by scanning electron microscopy (SEM).

Moreover, in Table 1 is included the glass fibre used was type $\mathrm{E}$
Table 1

Properties of materials used in towpregs.

\begin{tabular}{|c|c|c|c|c|}
\hline Property & $\begin{array}{l}\text { Glass } \\
\text { Fibre- }\end{array}$ & $\begin{array}{l}\text { Unmodified PET } \\
\text { (PET 1) }\end{array}$ & $\begin{array}{l}\text { Modified PET } \\
\text { (PET 2) }\end{array}$ & $\begin{array}{l}\text { Colour PET } \\
\text { (PET 3) }\end{array}$ \\
\hline $\begin{array}{l}\text { Source(stream } \\
\text { of } \mathrm{rPET} \text { ) }\end{array}$ & & Blue PET & Blue PET & Colour PET \\
\hline $\begin{array}{l}\text { Linear Density } \\
\quad(T e x)\end{array}$ & 2400 & - & - & - \\
\hline Density $\left(\mathrm{g} / \mathrm{cm}^{3}\right)$ & 2.650 & $1.326 \pm 0.007$ & $1.326 \pm 0.007$ & $\begin{array}{l}1.324 \pm \\
0.004\end{array}$ \\
\hline $\begin{array}{l}\text { Tensile Strength } \\
\text { (MPa) }\end{array}$ & 3500 & $45.2 \pm 7.2$ & $53.2 \pm 1.0$ & $21.5 \pm 1.0$ \\
\hline $\begin{array}{l}\text { Young Modulus } \\
\text { (MPa) }\end{array}$ & 76,000 & $2369.4 \pm 36.5$ & $2427.1 \pm 19.7$ & $\begin{array}{l}2579.0 \pm \\
84.4\end{array}$ \\
\hline $\begin{array}{l}\text { Powder particle } \\
\text { size }(\mu \mathrm{m})\end{array}$ & - & 200 & 200 & 200 \\
\hline $\begin{array}{l}\text { Fibre Diameter } \\
\qquad(\mu \mathrm{m})\end{array}$ & 17 & - & - & - \\
\hline $\begin{array}{l}\text { Intrinsic } \\
\text { viscosity (dl/ } \\
\text { g) }\end{array}$ & - & 0.8 & 0.68 & 0.66 \\
\hline $\begin{array}{l}\text { Molecular } \\
\text { weight (g/ } \\
\text { mol) }\end{array}$ & - & $23,675 \pm 174$ & $17,923 \pm 757$ & $\begin{array}{l}26,712 \pm \\
453\end{array}$ \\
\hline
\end{tabular}

2400tex (305 E-TYPE 30®) without any special coating from Owens Corning.

\subsection{Production of the pre-impregnated material}

The towpreg was produced in a developed dry powder coating installed in the Composite Material's Laboratory in ISEP- the Engineering School of Porto Polytechnic (Portugal) [20]. The machine is schematically depicted in Fig. 1. It consist of six main parts: a wind-off system, a fibres spreader unit, a heating section, a coating section, a consolidation unit and a wind-up section. The reinforced fibres are wound-off and pulled through a pneumatic spreader and then coated with the polymer powder by heating in a convection oven and made it passed into a polymer powder vibrating bath. A second oven allows softening the polymer powder promoting its adhesion to the fibre surface. Finally the towpreg is cooled down and wound-up on a spool [15].

This equipment allows the manufacture of towpreg, a preimpregnated material in which the powder polymer has an intimate contact with the fibres. The processing speed of the pre-impregnated material was $6 \mathrm{~m}$ per minute, with the first convection oven being setup to $700{ }^{\circ} \mathrm{C}$ and the second oven at $450{ }^{\circ} \mathrm{C}$. These processing conditions were optimized until a $45 \%$ matrix content was reached in the fiber. Fig. 2 shows an example of the physical form of the obtained towpreg.

As can be seen in Fig. 2, the contact angle between the polymer particles and the fibres suggests that they possess a good adhesion. This is important as makes the transformation of this towpreg easier.

\subsection{Pultrusion of towpreg composites}

The pre-impregnated towpregs were transformed by pultrusion in a developed $10 \mathrm{kN}$ pultrusion machine schematically shown in Fig. 3.

Pultrusion process was carried out at a speed of $0.2 \mathrm{~m}$ per minute, with 25 rovings of towpreg. The first pre-heating oven was set-up to 180 ${ }^{\circ} \mathrm{C}$. The pressurization and consolidation die was set to $280^{\circ} \mathrm{C}$, and the cooling die was set-up to $25^{\circ} \mathrm{C}$. The die used in this process allowed the manufacture of a $20 \times 2 \mathrm{~mm}^{2}$ pultruded composite profile. Fig. 4 shows the profile obtained by pultrusion of towpreg.

\subsection{Testing}

\subsubsection{Dynamic rheometry}

HAAKE Rheostress 600 dynamic rheometer was utilized to perform 


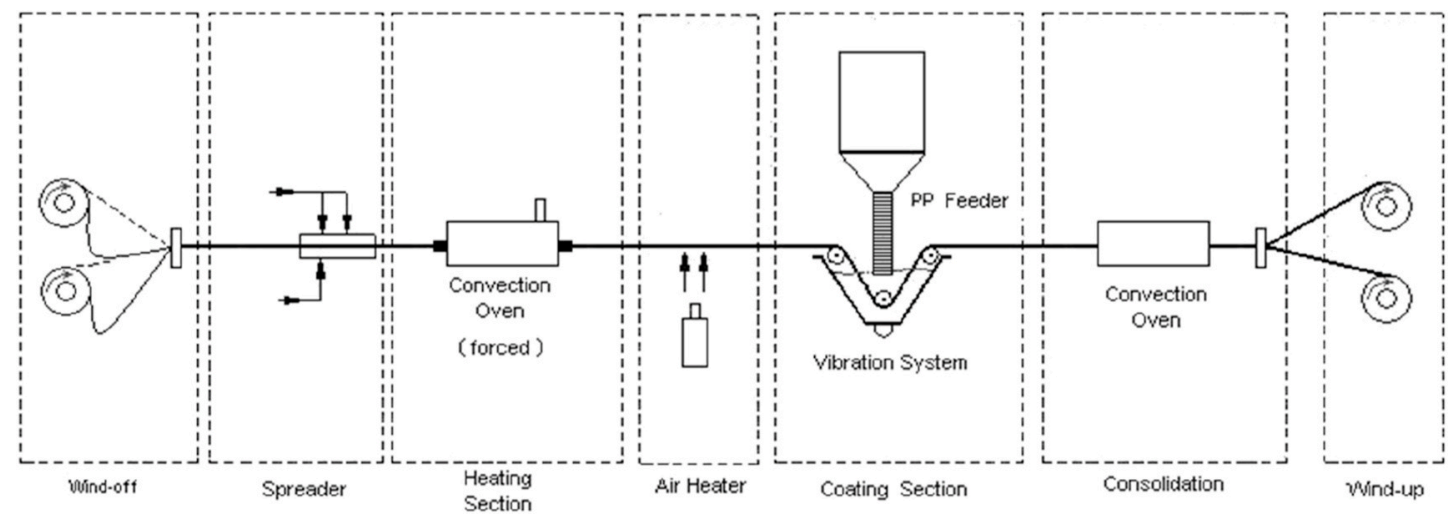

Fig. 1. Powder-coating line set-up.
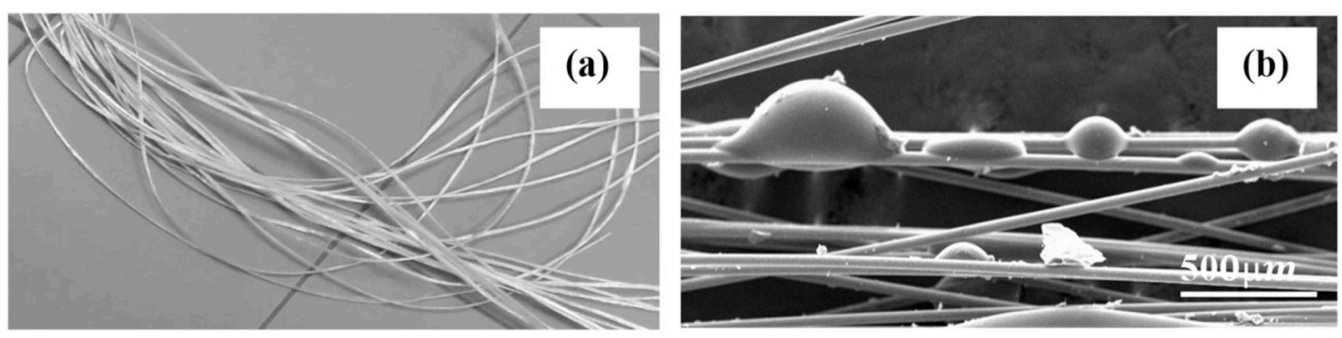

Fig. 2. Pre-impregnated towpreg semi-product.

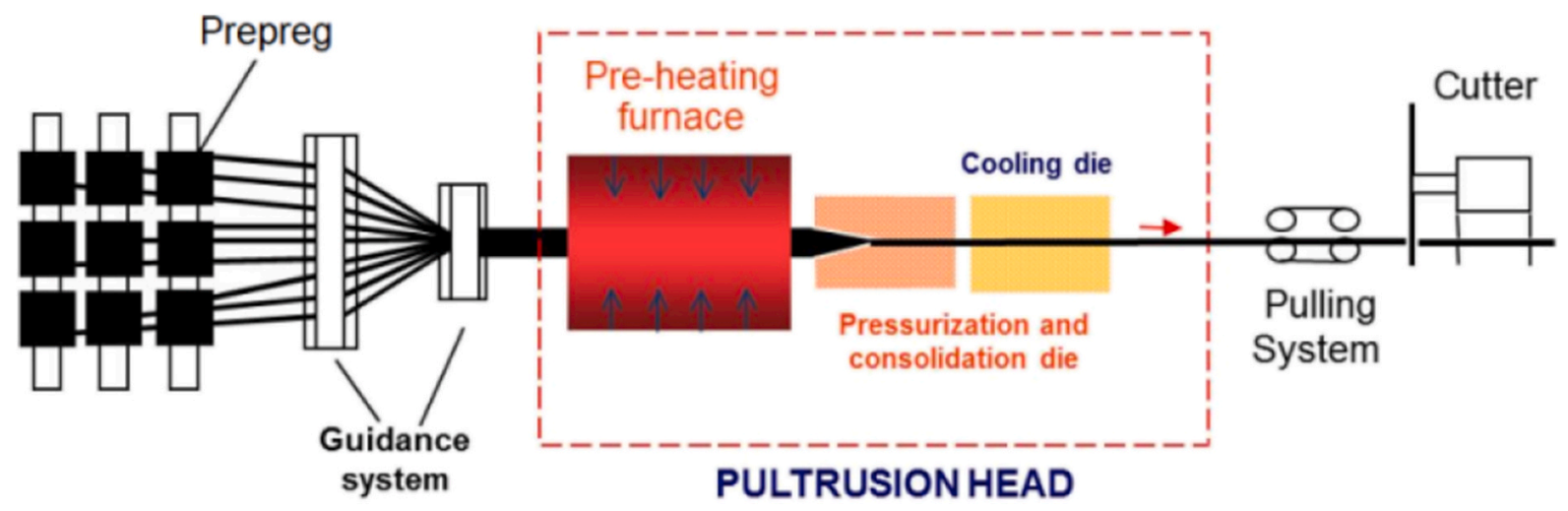

Fig. 3. Schematic diagram of the pultrusion line.

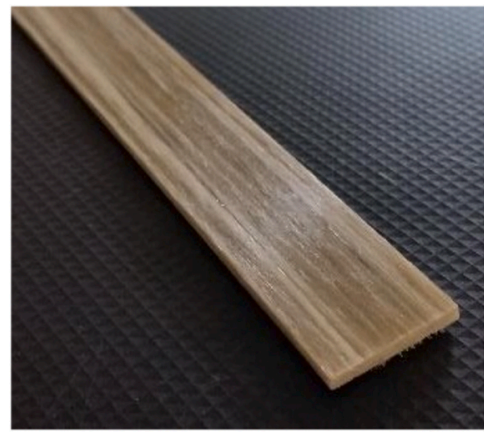

Fig. 4. Profile obtained by pultrusion.

the viscosity measurements in molten state of the three recycled PET samples. Plate-plate geometry $(20 \mathrm{~mm})$ and a selecting gap between plates of $1.6 \mathrm{~mm}$ were used. The complex viscosity $\left(\mu^{*}\right)$ was measured as a function of temperature from $265^{\circ} \mathrm{C}$ to $300{ }^{\circ} \mathrm{C}$ and frequency was set at $1 \mathrm{~Hz}$. In order to avoid possible molar mass changes during sample preparation, pellets were deposited directly into the pre-heated rheometer. It is important to know the measurement of the viscosity in melt since in this way we can know the rheological behavior that the material will have during the pultrusion process.

\subsubsection{Calcinations testing}

Glass fibre mass content in the composites was determined by using calcinations tests according to EN ISO 1172 standard. After calcinating the composite sample, using a crucible in a muffle furnace at $625{ }^{\circ} \mathrm{C}$ during $15 \mathrm{~min}$, the glass fibre mass fraction, $\omega_{f}$ was obtained by:

$\omega_{f}=\frac{m_{3}-m_{1}}{m_{2}-m_{1}}$

where $m_{1}, m_{2}$ and $m_{3}$ are: initial mass of the dry crucible $\left(m_{1}\right)$, initial mass of the dry crucible plus dried specimen $\left(m_{2}\right)$ and final mass of crucible plus residue after calcination $\left(m_{3}\right)$. Furthermore, by knowing the fibre and polymer densities, $\rho_{\mathrm{f}}$ and $\rho_{\mathrm{p}}$, respectively, the fibre mass 
fraction $\left(\omega_{f}\right)$ may be converted in fibre volume fraction $\left(v_{f}\right)$ by:

$v_{f}=\frac{w_{f} / \rho_{f}}{w_{f} / \rho_{f}+\left(1-w_{f}\right) / \rho_{p}}$

\subsubsection{Mechanical testing}

Mechanical testing was carried out in a Shimadzu AG-X equipment with a load cell of $100 \mathrm{kN}$. The flexural properties of the profiles obtained were determined under ISO 14125. This method was used to investigate the flexural behavior of the profiles and determine the flexural strength and flexural modulus. The span was $80 \mathrm{~mm}$ and the test speed was $2 \mathrm{~mm} / \mathrm{min}$. The dimension of the samples was $100 \times 20 \times 2$ $\mathrm{mm}^{3}$. The experimental results were compared with theoretical ones that can be predicted by using the ROM (Rule Of Mixtures). The modulus of elasticity of the profiles is approximately equal to the arithmetic mean of the fibre and polymer modules, according to the relative volumetric ratio of each, according to the well-known rule of mixtures. That is to say:

$\mathrm{E}=\mathrm{E}_{\mathrm{f}} \cdot \mathrm{V}_{\mathrm{f}}+\mathrm{E}_{\mathrm{p}} \cdot \mathrm{V}_{\mathrm{p}}$

where: $E$ is equal to the profile modulus, $E_{f}$ and $E_{p}$ are the fibre and polymer modulus respectively and $V_{f}$ and $V_{p}$ are the volume fractions of the fibre and polymer.

Tensile test was carried out at a speed of $2 \mathrm{~mm} / \mathrm{min}$ according to ISO 527, and distance between grippers was $200 \mathrm{~mm}$. A $50 \mathrm{~mm}$ length strain gauge was used up to $0.3 \%$ strain, for a more accurate determination of the tensile modulus. Six specimens for each condition were tested, each with a dimension of $250 \times 20 \times 2 \mathrm{~mm}^{3}$.

\subsubsection{Morphological analysis}

The Olympus Bx60M-KP-M1E/K microscope analysis has been carried out in order to evaluate the dispersion of the fibre/matrix in the final profiles. The microscope test was done using $100 \mu \mathrm{m}$ lenses and $\mathrm{x}$ 10 zoom.

Scanning Electron Microscopy (SEM) was used to evaluate the fibre/ matrix adhesion of the composites after the flexural test [21]. A FESEM Hitachi H-7000 microscope was used. For testing, samples were vacuum coated with a thin layer of gold palladium alloy to make them conductive.

\section{Results and discussion}

\subsection{Dynamic rheometry}

For pultrusion, is important to study the viscosity of the recycled PET during processing to better understand its behavior. In general, the manufacture of composite materials is better with lower viscosity in the melted state for better impregnation. To estimate the shear viscosity of the three polymers, Cox-Merz approach was used. This approach stipulates that complex viscosity may estimate shear viscosity [22].

Therefore, complex viscosity ( $\left.\eta^{*}\right)$ for the three recycled PET samples is plotted as function of temperature (Fig. 5). The vertical line in Fig. 5 indicates the processing temperature $\left(280{ }^{\circ} \mathrm{C}\right)$ used to produce the pultrusion profiles.

It is important to note that recycled PET materials used for pultrusion showed different rheological properties. Recycled PET 1 (which comes from blue PET) presented higher complex viscosity than PET 3 (colour PET). As can be observed, PET 1 chemically modified (corresponding with PET 2) achieved low viscosity values similar to PET 3.

\subsubsection{Calcinations testing}

Fig. 6 shows the results from calcinations test of the pultruded profiles. Moreover, the three PET pultruded profiles are compared with a polypropylene (PP) pultruded profile obtained by the same pultrusion technique [12].

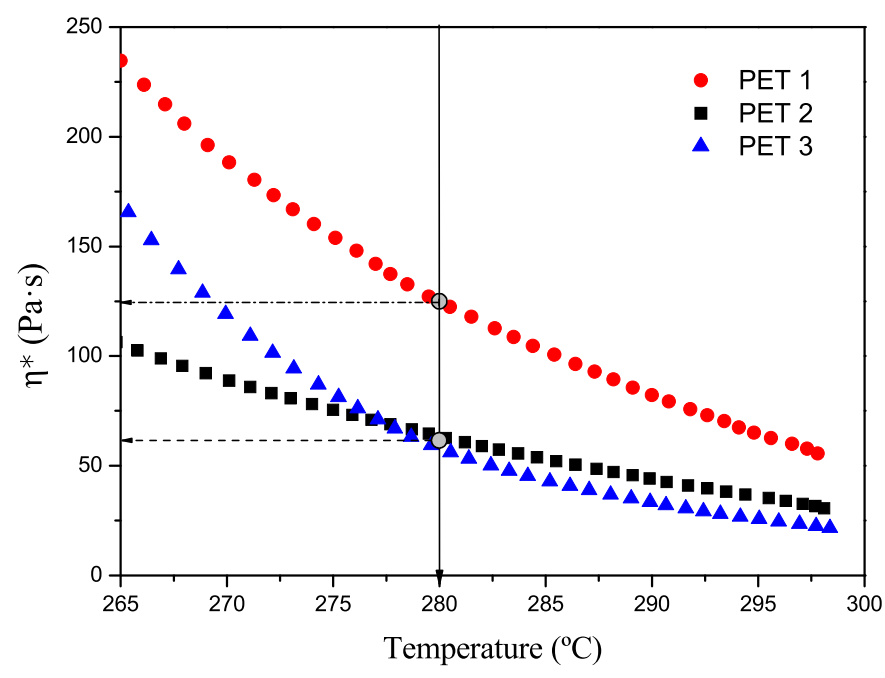

Fig. 5. Temperature sweeping of the materials used for pultrusion process.

PET 1 and PET 2 samples, which comes from the PET blue stream show similar and the highest volume fraction values. However, the fibre volume fraction of PET 3 (from colour stream waste) decreases slightly. This is due to the fact that this stream of recycled PET comes from a dirty waste stream and the presence of additives or adhesives could difficult the process of impregnation.

Comparing these results with another thermoplastic pultruded profile such as polypropylene, PET matrix showed higher fibre volume fraction. Polypropylene is a difficult polymer to transform into powder, the size of the particles is higher than PET. The higher particle size, means that impregnation in pultrusion will be much more difficult, requiring more production time (lower line speeds). This results in a worse distribution of polymer and fibers, and consequently allows the presence of voids, due to the longer time needed to achieve full impregnation.

\subsection{Mechanical testing}

Table 2 shows the flexural properties of the developed profiles. Moreover, flexural results of PET matrices are compared with flexural results of a PP profile [12,23], to better evaluate and compare the mechanical properties obtained on the composites processed from the different pre-impregnated products. Table 2 also presents the theoretical expected values and relative values of specific properties.

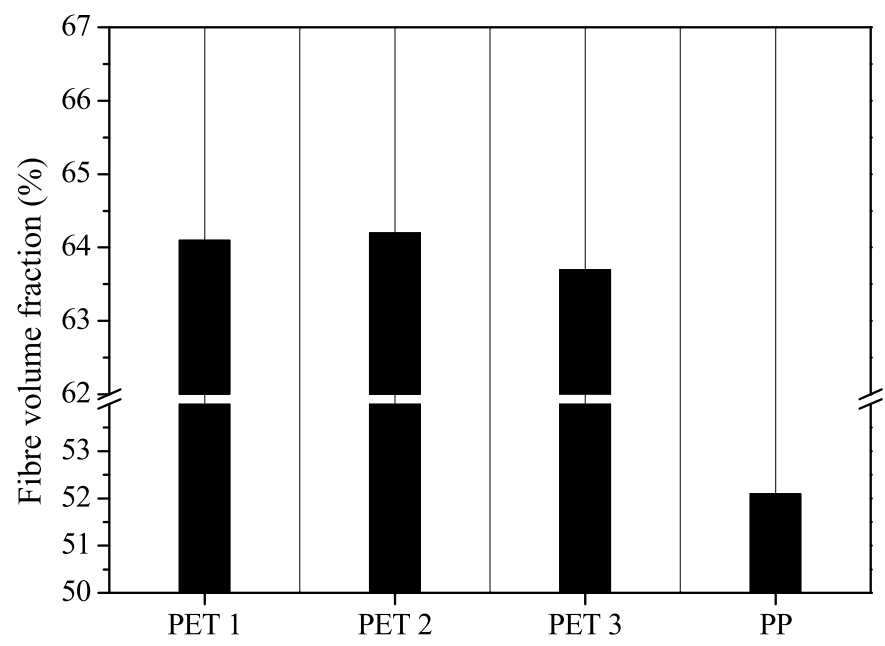

Fig. 6. Variation of fibre volume fraction with different matrices used in profiles. 
Table 2

Flexural properties of the profiles composites obtained from towpreg.

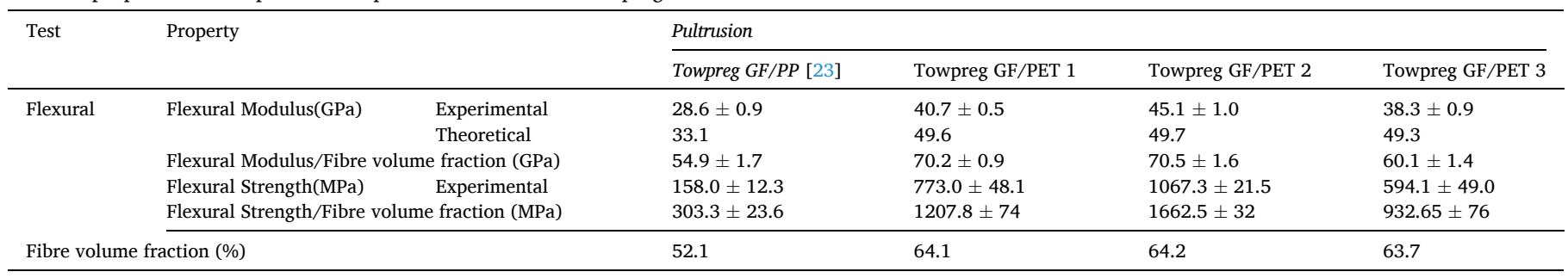

Table 2 shows that PET 1 and PET 2 which comes from the same stream, despite having different viscosity values, presented similar specific Flexural Modulus. While PET 3 showed the lowest values. This decrease may be due to the fact that PET 3 comes from coloured and more contaminated stream $[5,24]$. Waste from heterogeneous deposits of various coloured has been studied by other authors showing lower Modulus values than PET from blue post-consumer bottles [25]. As can be seen from Table 2 the experimental Flexural Modulus values obtained from composites are in agreement with the predicted theoretical ones showing more difference in PET 3 due to contamination of this material.

Regarding specific flexural strength, PET 2 showed an increase comparing with PET 1 . This can be due to low viscosity values of PET 2 (see rheological properties and intrinsic viscosity values, Fig. 5 and Table 1). The lower viscosity values of PET 2 improved the impregnation process of the matrix with the fibres and, consequently, better consolidation of the final profiles. On the other hand, PET 3 showed the lowest flexural strength (despite to have the lowest viscosity value). This is due to the high content of voids presented by this compound, which we will see later in the morphological analysis.

Compared with another thermoplastic pultruded profiles, such as polypropylene, it can be observed that using any of the recycled PET as polymeric matrix it is possible to produce profiles with improved bending properties (Table 2).

Table 3 shows tensile values of profiles obtained with recycled PET matrices. In addition, results are compared with tensile PP values [12, 23].

From tensile results, it can be observed that PET 2 (with lower viscosity values than PET 1) show the highest specific Modulus and Tensile strength. PET 3 (from colour PET waste) presents lowest viscosity values and the lowest Modulus and Tensile strength values as a consequence of contaminants present in this material. Therefore, in this case, its content of contaminants prevails more than its low viscosity. In this case, this material did not reach the properties of a PP.

\subsection{Morphological analysis}

During microscope analysis, the areas with fibre and polymer concentration were analysed to evaluate the distribution, the quality of impregnation and relative amount of voids. In a heterogeneous material, impregnation is an important factor to obtain a material with predictable properties and to obtain the potential of the materials involved [12, 26]. Fig. 7 show the analysis of the microscope of the three profiles obtained.
Analysing the images obtained by microscopy, it is possible to see in PET 1 that in the areas where there is a concentration of fibres, the absence of polymer around the fibres is evidenced. Comparing with PET 2 , zones with concentration of fibres have some polymer around the fibres, meaning an improvement of impregnation. In the case of PET 3 , there is not a regular dispersion of fibre and polymer, and the zones in which fibres are concentrated no polymer can be seen. Also, in PET 3 the amount of voids (in black) is higher than the other two.

In Fig. 8 we can observe the microscope images with polymer concentration.

The areas in which there is polymer concentration, fibres should be present to improve the homogeneity of the composite. By simple observation of Fig. 8, PET 3 can be seen with very low quantity of fibres, where in the case of PET 2 there is a more regular distribution of fibres when compared to PET 1.

It is possible to conclude in the case of PET 2 that the modification of the polymer improved the quality of impregnation when compared to PET 1, possibly due to lower polymer viscosity during pultrusion. As for PET 3, when compared to PET 1, the impregnation showed to be weaker, but further work including modification of this polymer should be done in future.

SEM was used in order to evaluate the adhesion of the polymers to the fibres after the flexural test [21]. The rupture of the samples on bending tests (Fig. 9) was visualized through SEM. Fig. 7 shows micrographs of glass fibre/PET samples pultruded profiles.

In Fig. 10 it can be seen how profiles with PET 1 and PET 2 showed the fibre surrounded by the polymer. In contrast, in the profile of PET 3 it was possible to observe the fiber separated from the matrix. This is in accordance with the mechanical properties where the profiles with PET 3 showed the lowest flexural values.

\section{Conclusions}

The pultrusion process by "towpreg" pre-impregnation allows concluding that it is possible to produce profiles from all three recycled PET materials. The mechanical results allow predicting the adequate use of recycled PET as matrix in pultruded profiles either in general or structural engineering applications. PET material is largely used due to its good characteristics and, therefore, generates a large amount of waste. These findings show a great advance for the recyclability that would reduce its accumulation in landfills. As a remarkable aspect is the recycling in high value and long-life applications such as pultruded profiles.

Table 3

Tensile properties of the profiles composites obtained from towpreg.

\begin{tabular}{|c|c|c|c|c|c|}
\hline \multirow[t]{2}{*}{ Test } & \multirow[t]{2}{*}{ Property } & \multicolumn{4}{|l|}{ Pultrusion } \\
\hline & & Towpreg GF/PP [23] & Towpreg GF/PET 1 & Towpreg GF/PET 2 & Towpreg GF/PET 3 \\
\hline \multirow[t]{4}{*}{ Tension } & Modulus(GPa) Experimental & $33.9 \pm 1.5$ & $47.3 \pm 1.8$ & $50.0 \pm 0.9$ & $45.3 \pm 0.3$ \\
\hline & Modulus/Fibre volume fraction (GPa) & 63.5 & 73.8 & 77.8 & 71.11 \\
\hline & Tensile strength (MPa) Experimental & $>336.3 \pm 22.3$ & $351.6 \pm 51.8$ & $441.7 \pm 23.9$ & $243.6 \pm 33.9$ \\
\hline & Tensile strength/Fibre volume fraction (MPa) & $>645.5 \pm 42.8$ & 548.5 & 688.0 & 382.41 \\
\hline \multicolumn{2}{|c|}{ Fibre volume fraction (\%) } & 52.1 & 64.1 & 64.2 & 63.7 \\
\hline
\end{tabular}




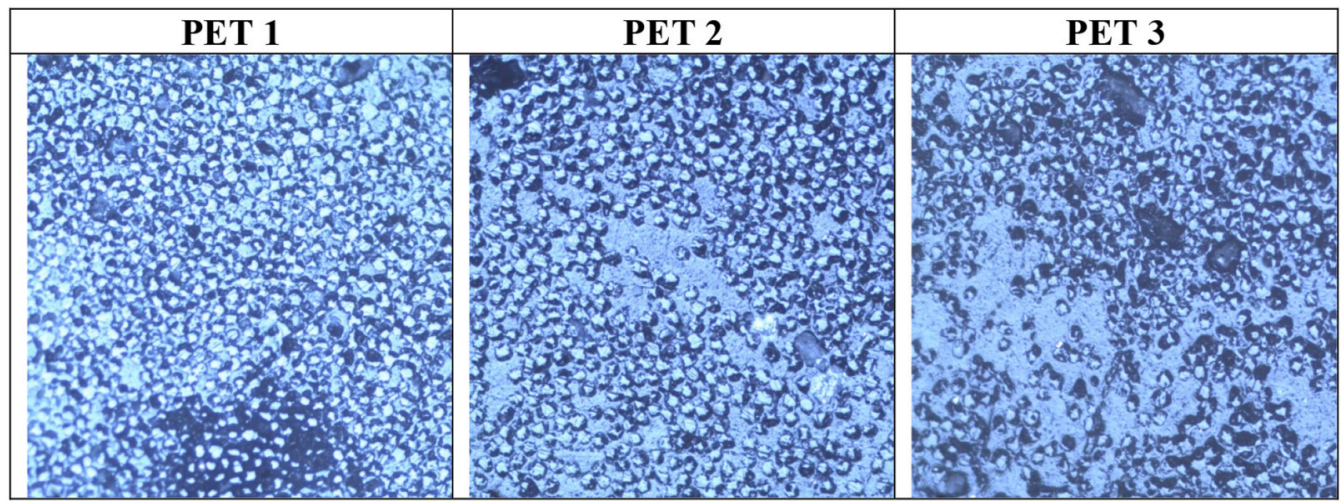

Fig. 7. Microscope images of areas with fibre concentration.

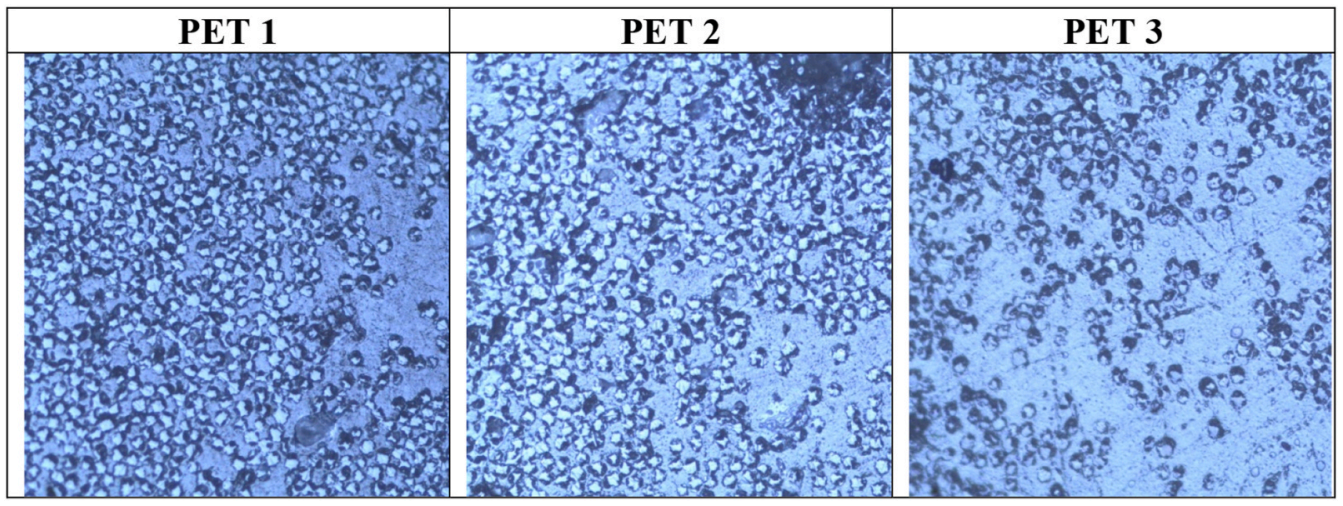

Fig. 8. Microscope images of areas with polymer concentration.

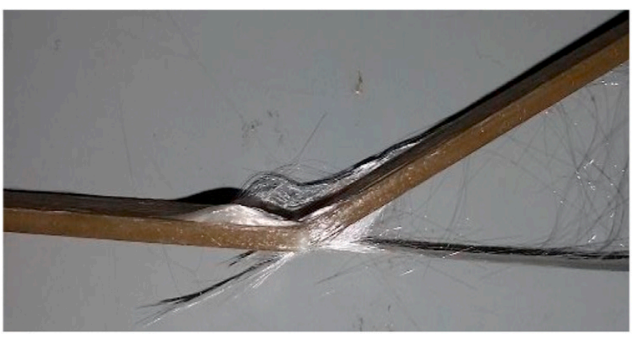

Fig. 9. Breakage fracture of essay profile.

The main differences between results lie in the different origin of the recycled material. Materials from PET blue streams (PET 1 and PET 2) used for the fabrication of profiles showed better mechanical properties. The one that presented lower viscosity values (PET 2) managed to obtain better distribution and, consequently, pultruded profiles with better mechanical properties. On the other hand, pultruded profiles obtained from PET 3 (colour stream PET) had the lowest Modulus values showing worse fiber and matrix homogeneity. However, in this case, the achievement of more benefit for this material is very interesting as it is not currently recycled.

\section{Author statement}

M. Asensio ${ }^{\mathrm{a}}$ : Investigation, Writing, Original Draft.

P. Estandiari ${ }^{\mathrm{b}}$ : Writing, Conceptualization, Resources.

K. Nuñez ${ }^{c}$ : Writing, Review \& Editing, Investigation, Data Curation.

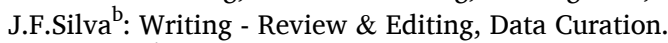

A. Marques ${ }^{\mathrm{d}}$ : Review \& Editing, Data Curation.

J.C.Merino $^{\mathrm{a}, \mathrm{b}}$ : Supervision, Project administration, Funding acquisition.

J.M. Pastor ${ }^{\mathrm{a}, \mathrm{b}}$ : Supervision, Review \& Editing , Project administration, Funding acquisition.

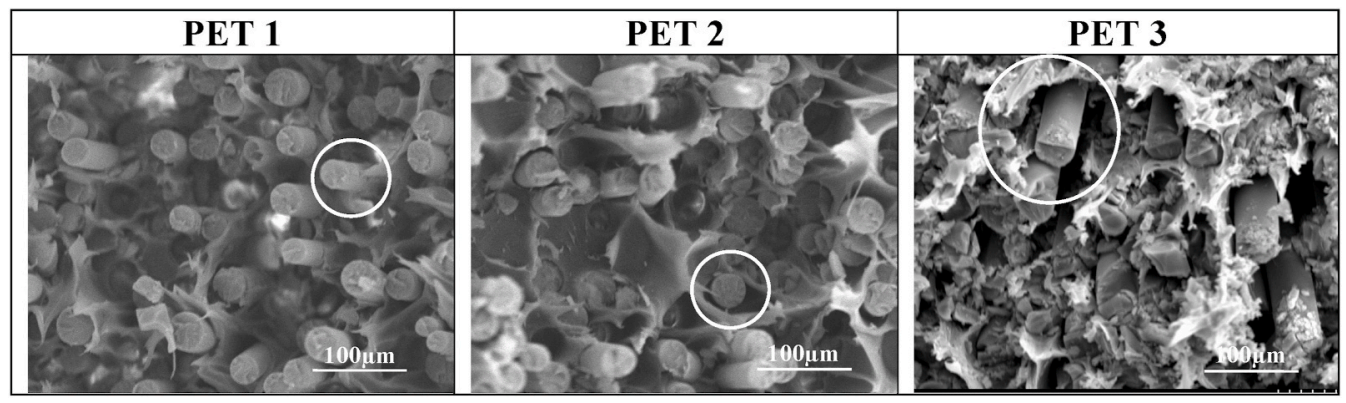

Fig. 10. SEM images of pultruded profiles. 


\section{Declaration of competing interest}

The authors declare that they have no known competing financial interests or personal relationships that could have appeared to influence the work reported in this paper.

\section{Acknowledgements}

The authors acknowledge the financial support from the "Ministerio de Economía y Competitividad" (Spain) through the project MAT201785101-C2, the Consejería de Educación, Junta de Castilla y León (project VA071G18 and grant to María Asensio) and Instituto para la Competitividad Empresarial de Castilla y León through the project CCTT2/ 18/VA/0002.

The authors also gratefully acknowledge the funding of Project NORTE-01-0145-FEDER-000022 - SciTech - Science and Technology for Competitive and Sustainable Industries, cofinanced by Programa Operational Regional do Norte (NORTE2020), through Fundo Europeu de Desenvolvimento Regional (FEDER).

\section{Appendix A. Supplementary data}

Supplementary data to this article can be found online at https://doi. org/10.1016/j.compositesb.2020.108365.

\section{References}

[1] Al-Sabagh AM, Yehia FZ, Eshaq G, Rabie AM, ElMetwally AE. Greener routes for recycling of polyethylene terephthalate. Egypt J Pet 2016;25:53-64. https://doi. org/10.1016/j.ejpe.2015.03.001.

[2] Jankauskaite V. Recycled polyethylene terephthalate waste for different application solutions. Environ Res Eng Manag 2016;72:5-7. https://doi.org/ 10.5755/j01.erem.72.1.15260.

[3] Awaja F, Pavel D. Recycling of PET. Eur Polym J 2005;41:1453-77. https://doi. org/10.1016/j.eurpolymj.2005.02.005.

[4] Ares Pernas AI, Abad López MJ, González Rodríguez MV, López M del MC, Latorre AL, López Vilariño JM. Assessing changes on poly(ethylene terephthalate) properties after recycling: mechanical recycling in laboratory versus postconsumer recycled material. Mater Chem Phys 2014;147:884-94. https://doi.org/10.1016/j. matchemphys.2014.06.034.

[5] Cruz SA, Scuracchio CH, Fitaroni LB, Oliveira C. The use of melt rheology and solution viscometry for degradation study of post-consumer poly(ethylene terephthalate): the effects of the contaminants, reprocessing and solid state polymerization. Polym Test 2017;60:236-41. https://doi.org/10.1016/j. polymertesting.2017.03.026.

[6] Kazemi Najafi S. Use of recycled plastics in wood plastic composites - a review. Waste Manag 2013;33:1898-905. https://doi.org/10.1016/j. wasman.2013.05.017.

[7] Elamri a, Abid K, Harzallah O, Lallam a. Characterization of recycled/virgin PET polymers and their composites. Am J Nano Res Appl Am J Nano Res Appl Spec
Issue Nanocompos Coat Manuf 2015;3:11-6. https://doi.org/10.11648/j.nano. s.2015030401.13.

[8] Gil H, Zuleta AA. Physical and mechanical properties of recycled PET composites. Civ Eng J 2019;4. https://doi.org/10.14311/CEJ.2019.04.0045. 2019.

[9] Miller AH, Dodds N, Hale JM, Gibson AG. High speed pultrusion of thermoplastic matrix composites. Compos Part A Appl Sci Manuf 1998;29:773-82. https://doi. org/10.1016/S1359-835X(98)00006-2.

[10] Nickels L. The future of pultrusion. Reinforc Plast 2019;63:132-5. https://doi.org/ 10.1016/j.repl.2019.01.003.

[11] Mayer C, Wang X, Neitzel M, Gmbh V. Macro- and micro-impregnation phenomena in continuous manufacturing of fabric reinforced. Compos Part A Appl Sci Manuf 1998;29:783-93. https://doi.org/10.1016/S1359-835X(98)00056-6.

[12] Novo PJ, Silva JF, Nunes JP, Marques AT. Pultrusion of fibre reinforced thermoplastic pre-impregnated materials. Compos B Eng 2016;89:328-39. https:// doi.org/10.1016/j.compositesb.2015.12.026.

[13] Novo PJ, Silva JF, Nunes JP, Marques AT. Advances in thermoplastic pultruded composites. ICCM Int Conf Compos Mater 2015;2015-July:19-24.

[14] McGregor OPL, Somashekar AA, Bhattacharyya D, McGregor OPL, Duhovic M. Preimpregnated natural fibre-thermoplastic composite tape manufacture using a novel process. Compos Part A Appl Sci Manuf 2017;101:59-71. https://doi.org/10.1016/ j.compositesa.2017.05.025.

[15] Silva João, Nunes João, Cab AM. Thermoplastic matrix composites from towpregs. 2013. https://doi.org/10.5772/46845.

[16] Novo PJ, Silva JF, Nunes JP, Van Hattum FWJ, Marques AT. Development of a new pultrusion equipment to manufacture thermoplastic matrix composite profiles. ECCM 2012 - Compos Venice, Proc 15th Eur Conf Compos Mater 2012:18-25.

[17] Friedrich K. Commingled yarns and their use for composites. 1999. p. 81. https:// doi.org/10.1007/978-94-011-4421-6_12.

[18] Asensio M, Nuñez K, Guerrero J, Herrero M, Merino JC, Pastor JM. Rheological modification of recycled poly(ethylene terephthalate): blending and reactive extrusion. Polym Degrad Stabil 2020;179:109258. https://doi.org/10.1016/j. polymdegradstab.2020.109258.

[19] Velde K Van De, Kiekens P, Mayer C, Wang X, Neitzel M, Gmbh V, et al. Pultrusion of unidirectional composites with thermoplastic matrices. Compos Part A Appl Sci Manuf 2015;54:191-6. https://doi.org/10.1016/S0263-8223(01)00110-6.

[20] Silva FJG, Amorim E, Baptista A, Pinto G, Campilho RDSG, Castro MRA. Producing hybrid pultruded structural products based on preforms. Compos B Eng 2017;116: 325-32. https://doi.org/10.1016/j.compositesb.2016.10.070.

[21] Van De Steene W, Verstockt J, Degrieck J, Ragaert K, Cardon L. An evaluation of three different techniques for melt impregnation of glass fiber bundles with polyamide 12. Polym Eng Sci 2018;58:601-8. https://doi.org/10.1002/pen.24789.

[22] Bair S, Yamaguchi T, Brouwer L, Schwarze H, Vergne P, Poll G. Oscillatory and steady shear viscosity: the Cox-Merz rule, superposition, and application to EHL friction. Tribol Int 2014;79:126-31. https://doi.org/10.1016/j. triboint.2014.06.001.

[23] Nunes JP, Silva JF, Santos MS, Novo PJ, Marques AT. Processing conditions and properties of continuous fiber reinforced GF/PP thermoplastic matrix composites manufactured from different pre-impregnated materials. ICCM Int Conf Compos Mater 2013;2013-July:3428.

[24] Torres N, Robin JJ, Boutevin B. Study of thermal and mechanical properties of virgin and recycled poly(ethylene terephthalate) before and after injection molding. Eur Polym J 2000;36:2075-80. https://doi.org/10.1016/S0014-3057 (99)00301-8.

[25] Elamri A, Lallam A, Harzallah O, Bencheikh L. Mechanical characterization of melt spun fibers from recycled and virgin PET blends. J Mater Sci 2007;42:8271-8. https://doi.org/10.1007/s10853-007-1590-1.

[26] Ishida O, Kitada J, Nunotani K, Uzawa K. Impregnation and resin flow analysis during compression process for thermoplastic composite production. Adv Compos Mater 2020:1-20. https://doi.org/10.1080/09243046.2020.1752964. 